\title{
Exploring How the Tone of Written Climate Change Communication Influences Coping Strategies
}

\author{
Ashley Park ${ }^{1}$ and Ashwani Vasishth ${ }^{\#}$ \\ ${ }^{1}$ Bergen County Technical High School, Teterboro, NJ, USA \\ \#Advisor
}

$\underline{\text { ABSTRACT }}$

The purpose of this study is to explore the influence that various tones of written climate change communication have on coping strategies. $126 \mathrm{New}$ Jersey college students responded to a quantitative questionnaire that had a passage on climate change written in one of the following tones: dreadful, cautiously optimistic, or hopeful. Students then answered 9 Likert scale questions that assessed their coping strategies in response to climate change: problem-focused, meaning-focused, and/or emotion-focused coping. Previous research has found that problem-focused and meaningfocused coping is positively correlated to pro-environmental behavior, but little research exists on what tones of climate change communication evoke problem-focused and meaning-focused coping. In this study, no statistical difference was found with respect to evoking problem-focused coping across the three tones. However, there were statistical differences in evoking meaning-focused and emotion-focused coping. Namely, those who responded to a cautiously optimistic or hopeful tone were more likely to resort to meaning-focused coping, and those who read a dreadful tone were more likely to apply emotion-focused coping. The findings of this study suggest using cautiously optimistic and hopeful tones in climate change communication in education to encourage environmental engagement and mitigate climate change related mental health concerns.

\section{Introduction}

Climate change may be the greatest threat facing humanity today. Although oftentimes framed as an environmental issue, climate change has impending consequences that will impact every aspect of human life and result in unprecedented migration to escape flooded and other uninhabitable regions; heightened competition for food due to droughts and widespread crop failure; extreme disruptions to international economies; and exacerbations to existing socio-economic injustices (Parry, 2020).

\section{Climate Anxiety}

Given the catastrophic nature of this phenomenon, climate change has an effect on psychological well being. Previous research has found that the "increased frequency and severity of extreme water events" are associated with increased levels of PTSD, depression, and anxiety, as natural disasters "disrupt educational, medical, economic, and transportation systems" and burden individuals (Morganstein \& Ursano, 2020). The increase in temperatures; migration due to rising sea levels, desertification, or other circumstances; competition of resources such as fertile land and clean water; and poor air quality from pollution are also linked to mental health concerns. However, more recent research is exploring the effect of climate change on individuals who have not experienced or perceived to have experienced any direct geological or physical consequences. There is evidence to indicate a connection between the perception of climate change and detrimental impacts on mental health; the most prevalent psychological phenomenon is climate anxiety, a condition "afflicting an increasing number of individuals who worry about the environmental 
crisis." Climate anxiety can be triggered by reflecting on how climate change threatens fundamental systems, understanding that there is no simple solution, and being uncertain about the future (Clayton, 2020).

The youth is more likely to be impacted by climate anxiety, and research has established that younger people display greater concern as they are more vulnerable to the destructive consequences that will likely unfold in the future (American Psychological Association, 2018). In a national poll conducted in 2019, 57\% of teenagers expressed that climate change makes them feel afraid (Kaplan \& Guskin, 2019), and numerous studies have shown that older adolescents and young adults are more likely to face mental health effects related to climate change than older adults (Corner et al., 2015).

\section{Climate Anxiety and Behavior}

It is important to explore the relationship between mental health and behavior because young people are inheriting a future that requires much action to prevent extreme damage from being inflicted. Some research has found that climate anxiety can lead to eco-paralysis, which inhibits people from taking effective action. However, other studies have found varying conclusions in which people who report feelings of distress about climate change are more than twice as likely to be motivated to reduce their harmful influence on the environment (American Psychological Association, 2020). In some studies, there was no overall correlation found between the feelings of anxiety and behavior (Clayton \& Karazsia, 2020).

\section{Climate Change Communication}

Whether or not people choose to change their behavior or take action in response to climate change is related to the way in which they receive information about climate change. Therefore, it is essential to have effective communication on climate change that uses strategies to evoke pro-environmental behavior without harming mental health. However, there are conflicting views on what constitutes effective communication. Emotion is one of the prominent elements of communication because it influences peoples' response to climate change (Damasio, 1994). Emotion has a direct impact on judgment and decision-making, serves as a prompt for engagement with an issue, and contributes to the formation of predispositions for action. Given the complex nature of emotions, there is an ongoing debate on what types of emotions in climate change communication are most conducive to pro-environmental behavior. Some studies claim that inducing strong emotional reactions such as worry and fear can change people's attitudes and become a source of motivation to change behaviors (Thomas et al., 2009). Other studies suggest that eliciting fear leads to avoidance and is not effective in promoting long-term environmental engagement due to the lack of perceived selfefficacy (Baron et al., 1994). Regarding positive emotions, the Broaden-and-Build theory demonstrates that they can "expand individual awareness of their connections to Earth's living systems" and increase their capacity to address environmental issues (Fredrickson 2001). Additionally In corroboration, appealing to the emotion of hope strengthens the perception of efficacy and likely increases the probability of positive engagement and pro-environmental behavior (Ojala, 2012). However, emotions are not "simple levers to be pulled to promote desired outcomes." Rather, they should be viewed as "one integral component of a cognitive feedback system guiding responses to challenging decision-making problems" (Chapman et. al., 2017).

\section{Coping Strategies}

In addition to emotions, coping strategies are another way to assess people's response to climate change. Coping is "cognitive and/or behavioral efforts to manage specific external and/or internal demands" and is used to handle various kinds of psychological stress. One of the most cited coping theories discusses the two main types of coping: emotionfocused coping which attempts to get rid of negative emotions evoked by a stressor, and problem-focused coping 
which concentrates on trying to solve the problem (Lazarus \& Folkman, 1984). A later study in Sweden educated 293 adolescents on the threat of climate change and assessed their coping strategies through a questionnaire, and three coping strategies were identified: problem-focused coping (e.g., "I will take direct action to address the problem"), de-emphasizing the severity of climate change (e.g, "I don't think anything serious will happen in my lifetime"), and meaning-focused coping (e.g., "I have faith in humanity"). The coping method of de-emphasizing the threat falls under the larger category of emotion-focused coping. Meaning-focused coping, which evokes positive feelings that draw on people's beliefs and values and serves as a buffer to hinder negative emotions, was added as the third coping strategy. It is not relevant in all stressful situations, but it pertains to circumstances where the stress cannot be removed or solved by the individual. The study concluded that problem-focused and meaning-focused coping are positively correlated to environmental engagement, whereas de-emphasizing the threat (emotion-focused coping) was negatively correlated to environmental engagement (Ojala, 2012). In a follow-up study by Ojala in 2019, she examines the relationship between coping strategies to climate change and pro-environmental behavior among young adults. The results found that problem-focused coping meaning-focused coping are positively correlated to pro-environmental behavior, whereas emotion-focused coping is negatively correlated to pro-environmental behavior.

\section{Communication and Coping Strategies}

Given the growing prevalence of climate anxiety, the extensive role that emotions play in communication, and the implications that can be drawn from coping strategies in response to the stress of climate change, it is essential to examine what emotions will elicit responses that encourage positive environmental engagement without causing extreme mental distress. Little research exists on how to communicate climate change in a way that evokes problemfocused and meaning-focused coping, which are linked to pro-environmental engagement and behavior. Therefore, this study explores how the tones used in written climate change communication-dreadful, cautiously optimistic, and hopeful-influence coping strategies among New Jersey college students. Although the results in previous research studies are mixed, a plausible conclusion for this study is that the students who read the passage that utilizes a dreadful tone will prompt emotion-focused coping because the elicited emotions may lead to avoidance, and conversely, the students who read the cautiously optimistic and hopeful passages are more likely to adopt meaning-focused and/or problem-based coping, as the elicited emotions may lead to positive encouragement. Overall, this study will contribute to the growing body of research that has conflicting views on what constitutes effective climate change communication by exploring how various tones of written climate change communication influence coping strategies.

\section{Methods}

\section{Participants and Sampling Method}

The study took place in winter of 2021, and data was collected by surveying college students who are from New Jersey or are currently enrolled in a school in New Jersey. A total of 126 students participated in the surveys, and all students provided active consent and confirmed that they were at least 18 years of age. To ensure confidentiality, students did not provide any personal or identifiable information. A majority of the participants are students at Ramapo College of New Jersey, and the surveys were shared through Professor Ashwani Vasishth after approval by the Ramapo College Institutional Review Board. Professor Ashwani Vasishth shared the surveys with college classes, and the data was collected through convenience sampling. Students were provided with a brief description of the study and were invited to fill out a survey. It is noted that this sampling method may result in voluntary response bias, in which students who have an interest in studying climate change were more likely to participate. Additionally, the surveys were shared on the researcher's personal social media pages to maximize the amount of data collected, and this approach could also 
result in voluntary response bias. The voluntary response bias may have skewed the results of the data, which limits the generalizability of the findings.

At the start of the survey, students were asked if they believe that climate change is influenced by human greenhouse gas emissions. Because all three passages are based on the notion that climate change is a scientifically proven phenomenon, all participants indicated that they believe climate change is influenced by human greenhouse gas emissions. If any participant had not indicated their belief in climate change, they would have been excluded from the data analysis, but such a case did not occur. This exclusion of climate deniers was added to the design of the method to remove any extreme outliers from the data, but given the fact that only about $70 \%$ of Americans believe in global warming, this aspect of the surveys may limit the generalizability of the study's findings (Ballew et. al., 2019).

\section{Surveys}

The study consists of three versions of the survey, and three groups of students each took one of the versions. Each version provided a brief passage on climate change, but in different tones: dreadful, cautiously optimistic, and hopeful. The tone is defined as the mood implied by the word choice in each of the passages, and the tone of the passages differs based on how the notion of the future, in regard to the climate crisis, is framed. In all three versions of the survey, the questions that students answer in response to the passage that they read are the same. All three groups responded to the Likert scale questions that assess the coping strategies (problem-focused coping, emotion-focused coping, meaning-focused coping) used in response to the text they read. Table 1, 2, and 3 display the three passages of the surveys. Table 4 displays the 9 statements for the Likert scale questions that were in the surveys.

Table 1. Dreadful Tone Passage (Wallace-Wells, 2020)

If your anxiety about global warming is dominated by fears of sea-level rise, you are barely scratching the surface of what terrors are possible, even within the lifetime of a teenager today. Indeed, without a significant adjustment to how billions of humans conduct their lives, parts of the Earth will likely become close to uninhabitable as soon as the end of this century.

The present tense of climate change — the destruction we've already baked into our future — is horrifying enough. Most people talk as if Miami and Bangladesh still have a chance of surviving; many scientists assume we'll lose them within the century, even if we stop burning fossil fuel in the next decade.

There are now, trapped in Arctic ice, diseases that have not circulated in the air for millions of years - in some cases, since before humans were around to encounter them — which means our immune systems would have no idea how to fight back when those prehistoric plagues emerge as the ice melts due to global warming.

Also, Americans will likely suffer a 70 percent increase in unhealthy ozone smog, the National Center for Atmospheric Research has projected. Already, more than 10,000 people die each day from the small particles emitted from fossil-fuel burning.

Table 2. Cautiously Optimistic Tone Passage (Roberts, 2019)

The climate is changing, and it's already destroying environments and killing lives. Much more damage is already baked into the future by recent greenhouse gas emissions. One way or another, when it comes to the effects of climate change, we're in for worse.

The international community has agreed, most recently in the Paris climate accord, to try to limit the rise in global average temperature to no more than 2 degrees Celsius above pre-industrial levels.

But what are the reasonable odds that the international community can reduce global carbon emissions enough to hit the 2 degree target?

For any hope of hitting 2 degrees, global emissions must peak and begin rapidly falling within the next dozen years. Accomplishing that would require immediate, bold, sustained, coordinated action around the world and major advancements in technology and politics. 
This rapid global change may seem unrealistic. But our history is replete with miraculously rapid changes. They have happened; they can happen again. And the more we envision them, and work toward them, the more likely they become.

Table 3. Hopeful Tone Passage (Cho, 2019)

These days, it can be hard to keep a positive attitude when it comes to climate change. The Intergovernmental Panel on Climate Change (IPCC) asserted that the impacts of $1.5^{\circ} \mathrm{C}$ of warming will be much more painful than expected. However, there are still many reasons to be optimistic about a sustainable future.

1) Coal is rapidly declining, and the fall of oil and natural gas is impending. The divestment from fossil fuels and a transition to renewable energy means cleaner air, cleaner water, and healthier humans.

2) In the last decade, clean energy technology has grown vastly more efficient and productive. In 2019, there were more renewable installations than coal, gas, and nuclear additions combined - and that was for the fifth year in a row. And China and India are both taking the lead in installing large-scale solar energy systems.

3) The U.S. has rejoined the Paris Climate Agreement, a global pact among 200 nations to avoid the worst impacts of climate change. The U.S. is the world's second-largest emitter of greenhouse gases and will play a key role in lessening global destruction.

4) Young people are taking action. In September 2020, the youth movement held a record-breaking strike with over 10 million participants worldwide. These protests are making statements to advocate for strong climate policies, and young leaders will study and fight for solutions to combat the crisis.

\subsection{Measures}

The COPE Inventory, which is a multidimensional scale that assesses the processes that people use to execute their response to stress, was used to design the survey questions. The COPE Inventory consists of statements that assess problem-focused coping and emotion-focused coping. It is commonly regarded as one of the standard methods to measure coping strategies and is used in many psychological studies. (Carver et. al., 1989). Three problem-focused coping statements and three emotion-focused coping statements were adapted and included in the surveys. See Table 4 for the statements. Another type of coping strategy, meaning-focused coping, is applied when the stressor cannot be removed or solved by the individual (Folkman, 2008). Because climate change is a global issue that cannot be removed or solved by the individual participants, the surveys also include three statements in regards to meaning-focused coping that were adapted from the coping scale used in "Young People's Coping Strategies Concerning Climate Change: Relations to Perceived Communication With Parents and Friends and Proenvironmental Behavior" (Ojala, 2019). In total, the surveys have 9 statements, and participants answer Likert scale questions to rate how true each statement is to them on a scale of one to four. One means "not true at all," two means "not true," three means "true," and four means "very true." All 9 statements were based off existing and credible scales that measure coping strategies to minimize the influence of the researcher's personal biases in the design of the surveys. Using Likert scale questions and collecting quantitative data supported this study's aim to identify statistically significant differences in the participants' coping strategies depending on the tone of the passage that they read. The statistical differences were identified through a Multivariate Analysis of Variance (MANOVA) test and Tukey post-hoc tests. Although the option of conducting interviews was considered, the assessment of coping strategies through interviews would likely have been less accurate due to factors such as participants' fear of judgement and lack of honesty when discussing their thoughts about climate change.

Because existing research presents conflicting views on how to most effectively communicate climate change, these results provide insight on the influence of a dreadful, cautiously optimistic, and hopeful tone on people's coping strategies, which will help formulate pedagogical approaches that promote positive environmental engagement while preventing extreme climate change related mental health concerns. 
Table 4. These are the statements on the surveys, and participants used a Likert scale to rate each statement based on how true the statement is to them, on a scale of 1-4.

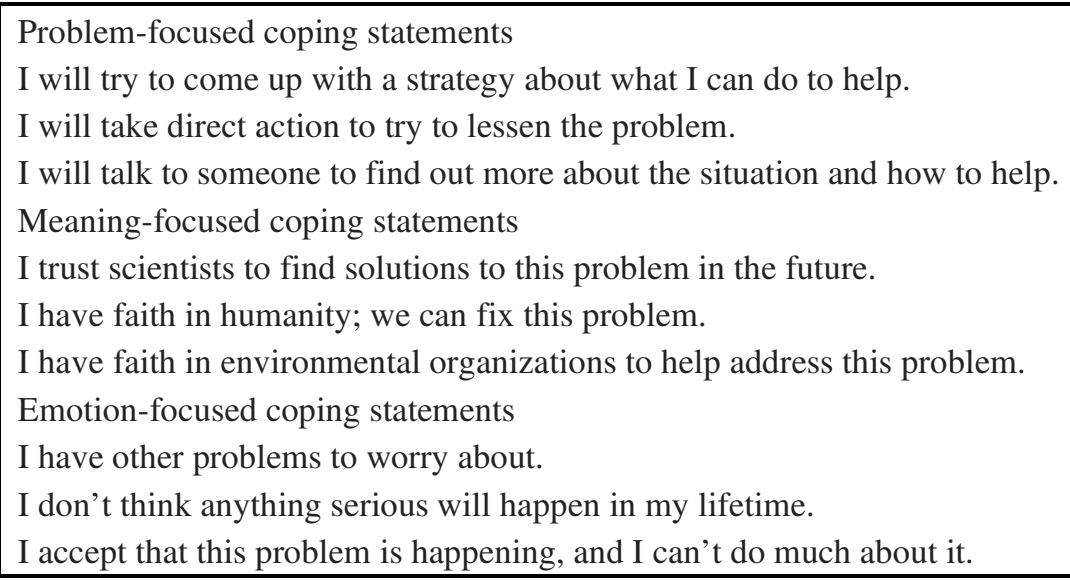

\section{Results}

\section{Means}

A total of 126 college students in New Jersey answered the surveys, with 46 responding to the dreadful tone survey, 46 responding to the hopeful tone survey, and 34 responding to the cautiously optimistic tone. They all responded to the same 9 Likert-scale questions where they ranked statements from 1, "not true at all" to 4 "very true." Table 5 presents the mean responses to each question and is organized by the written tone of climate change communication.

Table 5. Means and standard deviations of each of the statements for the three surveys.

\begin{tabular}{|c|c|c|c|c|c|c|c|c|c|c|}
\hline \multicolumn{2}{|l|}{ Tone } & $\begin{array}{l}\text { Proble } \\
\text { m1 }\end{array}$ & $\begin{array}{l}\text { Proble } \\
\mathrm{m} 2\end{array}$ & $\begin{array}{l}\text { Proble } \\
\text { m3 }\end{array}$ & $\begin{array}{l}\text { Meanin } \\
\text { g1 }\end{array}$ & $\begin{array}{l}\text { Meanin } \\
\text { g2 }\end{array}$ & $\begin{array}{l}\text { Meanin } \\
\text { g3 }\end{array}$ & $\begin{array}{l}\text { Emotio } \\
\text { n1 }\end{array}$ & $\begin{array}{l}\text { Emotio } \\
\text { n2 }\end{array}$ & $\begin{array}{l}\text { Emotio } \\
\text { n3 }\end{array}$ \\
\hline \multirow{3}{*}{$\begin{array}{l}\text { Cautiously } \\
\text { Optimistic }\end{array}$} & Mean & 2.85 & 2.91 & 3.29 & 3.41 & 2.56 & 3.12 & 2.38 & 1.62 & 2.35 \\
\hline & $\mathrm{N}$ & 34 & 34 & 34 & 34 & 34 & 34 & 34 & 34 & 34 \\
\hline & St.Dev & .857 & .830 & .676 & .701 & .894 & .808 & .922 & .888 & .981 \\
\hline \multirow[t]{3}{*}{ Dreadful } & Mean & 2.80 & 2.80 & 3.00 & 3.15 & 2.02 & 2.59 & 2.43 & 1.57 & 2.72 \\
\hline & $\mathrm{N}$ & 46 & 46 & 46 & 46 & 46 & 46 & 46 & 46 & 46 \\
\hline & St.Dev & .934 & .957 & .943 & .788 & .614 & .717 & .910 & .779 & .720 \\
\hline \multirow[t]{3}{*}{ Hopeful } & Mean & 2.83 & 2.83 & 3.00 & 3.20 & 2.57 & 2.80 & 2.33 & 1.52 & 2.20 \\
\hline & $\mathrm{N}$ & 46 & 46 & 46 & 46 & 46 & 46 & 46 & 46 & 46 \\
\hline & St.Dev & .926 & .950 & .943 & .806 & .688 & .833 & .790 & .691 & .749 \\
\hline
\end{tabular}

\section{MANOVA Test}

To identify any statistically significant differences in the responses among students who read passages of the varying tones, a Multivariate Analysis of Variance (MANOVA) test was run. Instead of running multiple Analysis of Variance (ANOVA) tests, a MANOVA test was run because there are at least 2 dependent variables; the responses to each of the 9 questions are the dependent variables. Also, the independent variable consists of at least two or more categorical, independent groups; the three groups that responded to the survey that used a dreadful, cautiously optimistic, or hopeful tone are the independent variables. This study satisfies all of the other assumptions that must be met when using a MANOVA test: the observations are independent because each participant is only in one group; the sample 
size is adequate because there are more participants in each group than the number of dependent variables; there are no univariate or multivariate outliers; there is multivariate normality; there is a linear relationship between each pair of dependent variables for each group of the independent variable; and there is no multicollinearity. Using Wilks' Lambda, a probability distribution used in multivariate hypothesis testing, a p-value of 0.032 was computed. Using an alpha level of 0.05 , we can conclude that the participants' responses are significantly different depending on the written tone in which climate change is discussed.

Table 6. The significance level of multivariate tests.

\begin{tabular}{|l|l|l|l|l|l|l|}
\hline Effect & Value & F & Hypothesis df & Error df & Sig. \\
\hline \multirow{4}{*}{ Tone } & Pillai's Trace & 2.39 & 1.748 & 18.000 & 232.000 & .033 \\
\cline { 2 - 7 } & Wilks' Lambda & .773 & 1.754 & 18.000 & 230.000 & .032 \\
\cline { 2 - 7 } & Hotelling's Trace & .278 & 1.760 & 18.000 & 228.000 & .031 \\
\cline { 2 - 7 } & Roy's Largest Root & .201 & 2.588 & 9.000 & 116.00 & .009 \\
\hline
\end{tabular}

\section{Tukey Post-hoc Tests}

Because a statistically significant difference was found among the responses to the surveys that used the three tones, Tukey post hoc tests were run to specifically identify where those differences lie. The responses to the three problemfocused coping Likert scale questions did not have any significant differences: the significance level to the statements "I will try to come up with a strategy about what I can do to help," "I will talk to someone to find out more about the situation and how to help," and "I will take direct action to try to lessen the problem," were $0.973,0.867$, and 0.253 respectively. Among the three meaning-focused coping Likert scale questions, two of them had responses that were significantly different. The responses to the first meaning-focused statement "I trust scientists to find a solution to this problem in the future" was not significantly different with a significance level of 0.301 . The responses to the next two meaning-focused statements "I have faith in humanity; we can fix this problem," and "I have faith in environmental organizations to fix this problem" were both significantly different depending on the written tone of climate change communication with significance levels of 0.001 and 0.013 respectively. Among the three emotion-focused coping Likert scale questions, one had responses that were significantly different depending on the tone. The responses to the statements "I have other problems to worry about" and "I don't think anything serious will happen in my lifetime" did not have significant differences with significance levels of 0.836 and 0.863 respectively, while the statement "I accept that this problem is happening and can't do much about it" had a significant different with a significance level of 0.008 . 


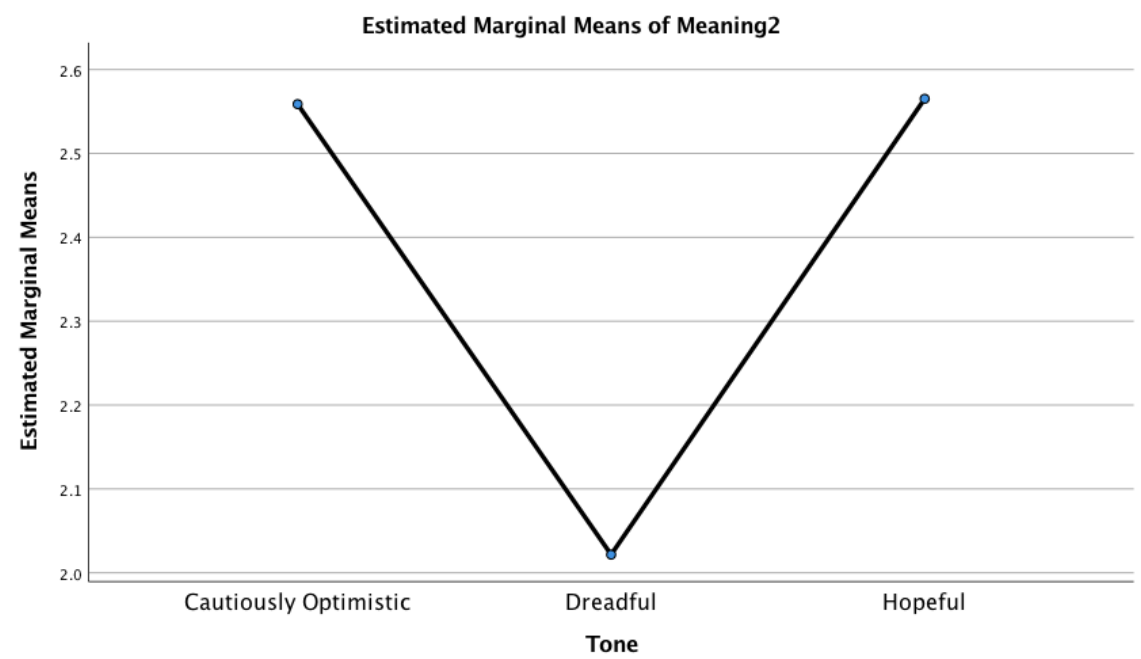

Figure 1. Significance level of 0.001 between dreadful and cautiously optimistic; and dreadful and hopeful for the meaning-focused coping statement, "I have faith in humanity; we can fix this problem."

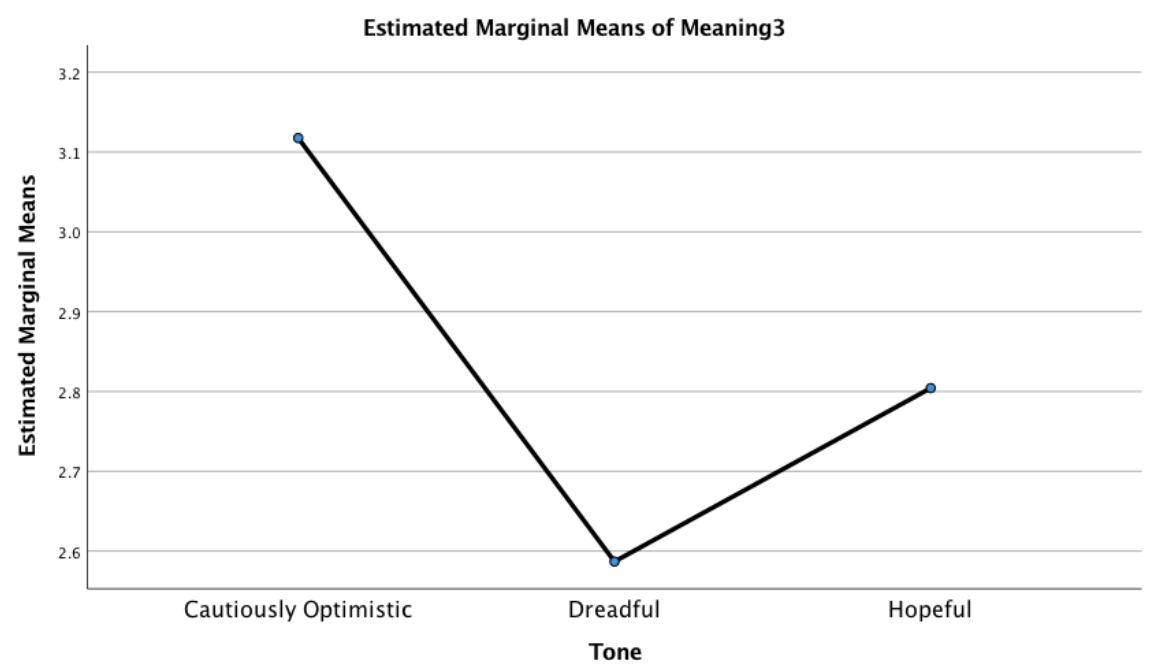

Figure 2. Significance level of 0.013 between dreadful and cautiously optimistic for the meaning-focused coping statement, "I have faith in environmental organizations to fix this problem." 


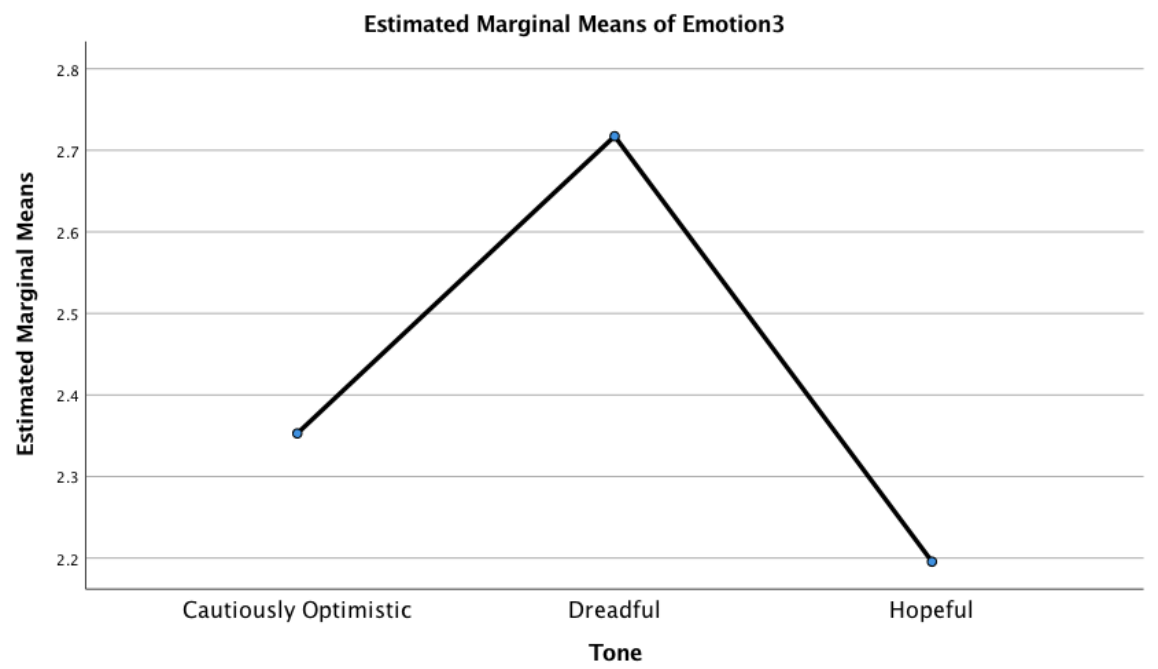

Figure 3. Significance level of 0.008 between dreadful and cautiously optimistic for the emotion-focused statement, "I accept that this problem is happening and can't do much about it."

\section{Discussion}

Existing studies find that certain coping strategies are correlated to pro-environmental behavior, but there is little research on how various tones of written climate change communication evoke these coping strategies. To fill this gap, this study explores how the written tones of dreadful, cautiously optimistic, and hopeful used to communicate climate change influence coping strategies among New Jersey college students. These findings can be applied in climate change education to discuss the topic in a way that encourages pro-environmental behavior and positive environmental engagement while also mitigating related mental health concerns. According to the data analysis, the researcher's initial hypotheses that those who read the dreadful tone passage would be more likely to use emotionfocused coping and those who read the cautiously optimistic and hopeful tone passages would be more likely to use meaning-focused coping is accepted. However, the hypothesis that those who responded to the cautiously optimistic and hopeful tone passages would be more likely to use problem-focused coping is rejected.

\section{Problem-Focused Coping}

Problem-focused coping, a strategy in which individuals attempt to solve or reduce the magnitude of a problem, is positively correlated with pro-environmental behavior and self-efficacy in regards to the climate crisis (Ojala, 2012). In this study, it was shown that there is no statistically significant difference among the three written tones of climate change communication in regards to evoking problem-focused coping. See figures 4, 5 and 6 in Appendix B for graphs showing the differences in means among the tones. The responses to the three problem-focused coping Likert scale questions (I will come up with a strategy about what I can do to help; I will talk to someone to find out more about the situation and how to help; I will take direct action to try to lesson the problem) were not influenced by the tone that the students read in their surveys. The means of the responses to those three questions in each of the surveys that use various tones are high, demonstrating a high degree of willingness to address climate change among the majority of students. This finding indicates that college students in New Jersey are trying to minimize their environmental impact and work towards future solutions. However, numerous studies have found that a high degree of problemfocused coping is also linked to anxious and/or depressed feelings in everyday life. Many researchers believe that 
utilizing problem-focused coping and putting effort to address a societal problem is associated with lower mental wellbeing (Clarke, 2006). The high response of problem-focused coping among participants regardless of the tone of the passage that students read suggests the widespread environmental awareness and pro-environmental mindsets of students in New Jersey while also highlighting the need to address the potential mental health issues that are evoked by the climate crisis.

\section{Meaning-Focused Coping}

Meaning-focused coping is a strategy in which people draw on their beliefs, values, and existential goals, and although it is typically not a relevant coping mechanism for everyday stressors, it is important to examine when people are facing societal problems that they have little control over. Among the three meaning-focused coping Likert scale questions, the responses to two of the questions were found to have a statistically significant difference depending on the tone of the passage students read. Specifically, those who read the dreadful toned passage rated the second meaning-focused coping Likert scale question (I have faith in humanity; we can fix this problem) lower than those who read the passage that used a cautiously optimistic tone or a hopeful tone. Similarly, those who read the passage that used a dreadful tone rated the third meaning-focused coping Likert scale question (I have faith in environmental organizations to solve this problem) lower than those who read the passage that used a cautiously optimistic tone. See figures 1 and 3 in the results section for graphs showing the differences in means among the tones. The low rating among students who responded to the dreadful toned passage demonstrates that they did not feel as much faith in humanity and in environmental organizations. In contrast, the higher rating of these statements show that those who read passages that are presented in a cautiously optimistic tone or a hopeful tone are more likely to utilize meaningfocused coping when confronting climate change. An experimental study found that those who have trust and place faith in larger societal groups that play a role in addressing climate change, such as environmental organizations and humanity as a whole, are more engaged in positive environmental intentions. Lacking faith in such larger societal groups leads to resignation and lack of motivation to put efforts towards combating global problems (Van Zomeren et al., 2010). Another study concluded that there is a strong correlation between using meaning-focused coping in response to climate change and engaging in pro-environmental behavior (Ojala, 2012). Additionally, multiple studies indicate that meaning-focused coping activates positive feelings that can serve as a buffer to the high level of negative emotions that are evoked by the climate crisis, so evoking meaning-focused coping is a potential method to reduce climate change related mental health concerns (Clayton, 2020). Because the participants who read a passage on climate change that used a cautiously optimistic and hopeful tone utilized meaning-focused coping more than those who read a passage that used a dreadful tone, this finding suggests that communicating climate change through cautiously optimistic and hopeful messaging encourages environmental engagement and pro-environmental behavior in a psychologically healthy manner.

\section{Emotion-focused coping}

Emotion-focused coping is a strategy in which individuals attempt to get rid of the problem through avoidance, distancing, and/or denial. Among the three emotion-focused Likert scale questions, there was a statistically significant difference in the responses to the third statement (I accept that this problem is happening, and I can't do much about it) between those who responded to the dreadful toned passage and those who responded to the hopeful toned passage. See figure 3 in the results section for the graph showing the differences in means among the tones. The students who responded to the dreadful tone passage rated this statement much higher, indicating their emotional reaction of feeling powerless and thus distancing themselves from the stressor of climate change. A study of adolescents and young adults found that resignation is a common coping strategy in response to feeling helpless when facing societal problems (Thearle \& Weinreich-Haste, 1986). Perhaps not surprisingly, those who use this type of emotion-focused coping demonstrate a low level of perceived self-efficacy are much less likely to behave pro-environmentally and be proactive 
in combating climate change (Ojala, 2012). For the other two statements of emotion-focused coping (I have other problems to worry about; I don't think anything serious will happen in my lifetime), there was no significant difference in the responses among the three tones. These two statements demonstrate denial as a reaction of fear when confronting a problem, but the mean responses for all three tones were relatively low, suggesting that New Jersey college students accept that the consequences of climate change are impending. See figures 8 and 9 in Appendix B for graphs showing the differences in means among the tones. Overall, these findings suggest that a dreadful tone in climate change communication is more likely to lead to feelings of resignation among New Jersey college students, but it does not lead to higher levels of denial compared to the other two tones.

\section{Limitations}

One of the limitations of this study is that the three passages in the surveys that the participants responded to were adapted from various digital articles. The articles were selected by the researcher, and the researcher defined the tones used in those articles, which introduces a bias. As stated in the introduction, the tone is defined as the mood implied by the word choice in each of the passages, and it differs based on how the notion of the future is framed, but there is no objective way of measuring tone. Due to this subjectivity, participants who read the same passage may have comprehended it slightly differently. Additionally, the surveys measured the immediate reactions of participants, and their responses indicate the coping strategies that they used directly after reading their passage. The conclusions and implications of this study may not be accurate predictors of long-term coping strategies in response to climate change. Indications of pro-environmental behavior and positive environmental engagement could be identified, but this study does not assess whether any changes or actions were implemented in the participants' lives. Reading one brief passage on climate change is not likely to heavily influence preconceived notions that the participants may have had about climate change or lead to major behavioral changes. It is also important to note the specific demographic of participants is: college-aged students in New Jersey. As the ones who most directly face the consequences of climate change, members of Generation $\mathrm{Z}$ havehas the greatest awareness and understanding of climate change (American Psychological Association, 2018). Other considerations to take into account when looking at survey respondents are that aAccording to national polls, New Jersey ranks as one of the top ten most politically liberal states, and the current governor, Phil Murphy, is regarded as one of the most environmentally conscious governors in the United States (Kelly, 2020). Given New Jersey's political climate, the implications of this study may not be relevant in guiding climate change communication and education in other states, especially states that are politically conservative. Lastly, all participants believe that climate change is influenced by human greenhouse gas emissions, so the issue of climate denial is not addressed in this study.

\section{Implications}

The findings of this study can be used to guide climate change communication in education. Framing climate change in a cautiously optimistic and hopeful light in schools can foster pro-environmental behavior and positive environmental engagement among students. When based in scientific fact, optimism and hope are not illusory feelings, but rather sources of motivation (Ojala, 2011). Governor Murphy of New Jersey has announced the requirement of climate change education in all K-12 public schools starting in the fall of 2021 (Williams, 2020). This study suggests that climate change in schools should be framed in a cautiously optimistic manner to explain the dangers and consequences while discussing the positive changes and innovative work that is being done towards solutions. Incorporating hope into the education can also evoke meaning-focused coping and prevent students from feeling resignation and helplessness. As students learn to utilize meaning-focused coping while learning about climate change, they will feel more motivated to act pro-environmentally in their everyday lives as well as fight for systemic and policy changes to create a larger impact. Therefore, school curriculums should incorporate climate change education 
in a cautiously optimistic and hopeful light to inspire positive environmental engagement in a psychologically healthy way, limit the usage of harmful and ineffective coping strategies, and protect against mental health concerns, such as climate anxiety.

\section{Future Studies}

Because this study only assesses the immediate reactions of participants after reading a passage on climate change, future studies should explore how various tones of climate change communication may influence long-term coping strategies and behavioral changes. Also, a future study could utilize a similar design and compare the coping strategies utilized by students who are already involved in environmental activism to those who are not yet involved in environmentalism. The influence of the various tones may be different among those two groups, which may provide implications for communicating with people of varying levels of environmental engagement. Additionally, this study can be replicated using a different demographic, such as young children, older adults, or students of different states in the United States, which may lead to findings about how to effectively evoke pro-environmental mindsets and behavior among people of various groups.

\section{Acknowledgments}

I thank Mr. Daniel Olivo (Bergen County Technical High School - Teterboro) for his guidance in AP Research and Professor Ashwani Vasishth (Ramapo College of New Jersey) for his assistance in expanding the reach of my questionnaire.

\section{References}

American Psychological Association. (2020). Majority of US adults believe climate change is most important issue today. American Psychological Association. https://www.apa.org/news/press/releases/2020/02/climate-change.

American Psychological Association. (2018). Stress in America. American Psychological Association. https://www.apa.org/news/press/releases/stress/2018/stress-gen-z.pdf

Azeiteiro, U. M., Azul, A. M., Filho, L. W., Manolas, E., \& McGhie, H. (2018). Handbook of Climate Change Communication: Vol. 1 Theory of Climate Change Communication. Springer International Publishing.

Baron, R., Logan, H., Lilly, J., Inman, M., \& Brennan, M. (1994). Negative Emotion and Message Processing. Journal of Experimental Social Psychology, 30(2), 181-201. https://doi.org/10.1006/jesp.1994.1009

Carver, C. S., Scheier, M. F., \& Weintraub, J. K. (1989). Assessing coping strategies: A theoretically based approach. Journal of Personality and Social Psychology, 56(2), 267-283. https://doi.org/10.1037/00223514.56.2.267

Chapman, D. A., Lickel, B., \& Markowitz, E. M. (2017). Reassessing emotion in climate change communication. Nature Climate Change, 7(12), 850-852. https://doi.org/10.1038/s41558-017-0021-9

Cho, R., (2019, July 31). Six Reasons to Be Hopeful About Fighting Climate Change. State of the Planet. https://news.climate.columbia.edu/2019/02/13/hope-fighting-climate-change/. 
Clarke, A. T. (2006). Coping with Interpersonal Stress and Psychosocial Health Among Children and Adolescents: A Meta-Analysis. Journal of Youth and Adolescence, 35(1), 11-24. https://doi.org/10.1007/s10964-005-9001-X

Clayton, S., \& Karazsia, B. T. (2020). Development and validation of a measure of climate change anxiety. Journal of Environmental Psychology, 69, 101434. https://doi.org/10.1016/j.jenvp.2020.101434

Corner, A., Roberts, O., Chiari, S., Völler, S., Mayrhuber, E. S., Mandl, S., \& Monson, K. (2015). How do young people engage with climate change? The role of knowledge, values, message framing, and trusted communicators. Wiley Interdisciplinary Reviews: Climate Change, 6(5), 523-534. https://doi.org/10.1002/wcc.353

Damasio, A. R. (2000). Descartes' error: emotion, reason, and the human brain. Harper/Collins.

Fredrickson B. L. (2001). The role of positive emotions in positive psychology. The broaden-and-build theory of positive emotions. The American psychologist, 56(3), 218-226. https://doi.org/10.1037//0003-066x.56.3.218

Kaplan, E. (2019, November 27). Most American teens are frightened by climate change, poll finds, and about 1 in 4 are taking action. Retrieved January 23, 2021, from https:/www.washingtonpost.com/science/most-american-teensare-frightened-by-climate-change-poll-finds-and-about-1-in-4-are-taking-action/2019/09/15/1936da1c-d639-11e99610-fb56c5522e1c story.html

Kelly, M. (2020, November 4). NJ suburbs map Democrats' paths forward in 2020 and beyond: Kelly. North Jersey Media Group. https://www.northjersey.com/story/news/columnists/mike-kelly/2020/11/04/nj-suburbs-democratsmap-course-national-dominance/6129405002/.

Lazarus, R. S., \& Folkman, S. (1984). Stress, appraisal, and coping. Springer.

Morganstein, J. C., \& Ursano, R. J. (2020, January 2). Ecological Disasters and Mental Health: Causes, Consequences, and Interventions. Frontiers. https://doi.org/10.3389/fpsyt.2020.00001.

Ojala, M. (2012). Hope and climate change: the importance of hope for environmental engagement among young people. Environmental Education Research, 18(5), 625-642. https://doi.org/10.1080/13504622.2011.637157

Ojala, M., \& Bengtsson, H. (2018). Young People's Coping Strategies Concerning Climate Change: Relations to Perceived Communication With Parents and Friends and Pro Environmental Behavior. Environment and Behavior, 51(8), 907-935. https://doi.org/10.1177/0013916518763894

Parry, E. (2020). The Greatest Threat To Global Security: Climate Change Is Not Merely An Environmental Problem. United Nations. https://www.un.org/en/chronicle/article/greatest-threat-global-security-climate-changenot-merely-environmental-problem.

Roberts, D. (2018, December 28). The case for "conditional optimism" on climate change. Vox. https://www.vox.com/energy-and-environment/2018/12/28/18156094/conditional-optimism-climate-change.

Thomas, E. F., McGarty, C., \& Mavor, K. I. (2009). Transforming “Apathy Into Movement”:The Role of Prosocial Emotions in Motivating Action for Social Change. Personality and Social Psychology Review, 13(4), 310-333. https://doi.org/10.1177/1088868309343290

Thearle, L., \& Weinreich-Haste, H. (1986). Ways of Dealing with the Nuclear Threat: Coping and Defense Among British Adolescents. International Journal of Mental Health, 15(1-3), 126-142. https://doi.org/10.1080/00207411.1986.11449024 
Van Zomeren, M., Spears, R., \& Leach, C. W. (2010). Experimental evidence for a dual pathway model analysis of coping with the climate crisis. Journal of Environmental Psychology, 30(4), 339-346.

https://doi.org/10.1016/j.jenvp.2010.02.006

Wallace-Wells, D. (2020). The uninhabitable earth: life after warming. Tim Duggan Books.

Williams, D. (2020, June 4). New Jersey is the first state to add climate change to its $K$-12 education standards. CNN. https://www.cnn.com/2020/06/04/us/new-jersey-climate-schools-scn-trnd/index.html. 